www.jmscr.igmpublication.org

Impact Factor 5.84

Index Copernicus Value: 83.27

ISSN (e)-2347-176x ISSN (p) 2455-0450

crossref DOI: https://dx.doi.org/10.18535/jmscr/v5i7.177

Journal Of Medical Science And Clinical Research

\title{
Comparative Study of Laura Mitchell's Physiological Relaxation Technique Versus Jacobson's Progressive Relaxation Technique on Severity of Pain And Quality of Life in Primary Dysmenorrhea: Randomized Clinical Trial
}

\author{
Authors \\ Dr Ganesh B. MPT PhD ${ }^{1}$, Ashma Chodankar BPT ${ }^{2}$, Bhakti Parvatkar BPT \\ ${ }^{1}$ Professor, Kle's Institute of Physiotherapy \\ Email:drganeshnssofficer@gmail.com \\ ${ }^{2}$ Intern, Kle's Institute of Physiotherapy \\ Email:archodankar@gmail.com \\ ${ }^{3}$ Intern, Kle's Institute of Physiotherapy \\ Email: parvatkarbhakti@yahoo.com
}

\begin{abstract}
Aim: To Evaluate which relaxation technique is more effective on severity of pain and quality of life in primary dysmenorrhea.

Objectives: To compare the effect of Laura Mitchell's physiological versus Jacobson's progressive relaxation technique on severity of pain and quality of life in primary dysmenorrhea. To study the effect of Laura Mitchell's physiological and Jacobson's progressive relaxation technique on severity of pain and quality of life in primary dysmenorrhea.

Methods: Two groups were made consisting of group $A(n=17)$ and group $B(n=17)$ under the age of 18 to 22 years with primary dysmenorrhea and were randomly assigned to the study. Moos menstrual distress questionnaire $(M M D Q)$ was used as screening tool and Numeric pain rating scale to assess severity of pain and quality of life scale by American chronic pain association to assess quality of life were administered pre intervention and post intervention. Group A was given Laura Mitchell s physiological relaxation technique and Group B was given Jacobson's progressive relaxation technique for 30 minutes twice a day for two consecutive cycles.

Result: Significant decrease in the intensity of pain was seen in group Aas compared to group $B$ and significant improvement of quality of life was seen in group B as compared to group A.

Conclusion: Laura Mitchell's physiological relaxation technique was more effective in reducing severity of pain and Jacobson's progressive relaxation technique was more effective in improving quality of life in primary dysmenorrhea. Both the relaxation techniques improved quality of life and reduced absenteeism and stress levels and it is easy, cheap and has no side effects

Keywords: Dysmenorrhea, Laura Mitchell's physiological and Jacobson's progressive relaxation techniques, pain and quality of life.
\end{abstract}

\section{INTRODUCTION}

The term dysmenorrhea comes from Greek word for difficult monthly flow and describes painful menstruation. Majority of women suffer from dysmenorrhea, which is the most common gynaecological disorders ${ }^{1}$. 
It is a periodic discharge of blood mucus and epithelial cells that occur at monthly intervals throughout the reproductive cycle ${ }^{2}$.

The prevalence of primary dysmenorrhea in women in India is about $90 \%{ }^{3}$.

Dysmenorrhea is characterized by cramping pelvic pain before or during the onset of menstrual cycle, lasting up to 1-3 days ${ }^{4}$

Dysmenorrhea can lead to absenteeism from school, or college and decreased work efficiency. Several studies have shown that adolescents with primary dysmenorrhea report that it effects their academic performance, social and sports activities ${ }^{5,6}$.

A study showed that more than $50 \%$ of all menstruating women experienced some discomfort. It has been reported that probably 5 to $10 \%$ of girls in their late teens suffer from severe spasmodic dysmenorrhea interpreting their educational and social life ${ }^{7}$. The etiology of primary dysmenorrhea is not precisely understood, but most symptoms can be explained by the action of uterine prostaglandins, particularly PGF2- Alfa ${ }^{8}$.

As there is an increase in the production and release of prostaglandins (mainly PGF2) in the endometrium during the menstruation, it causes an increase in the frequency of uterine contraction, which causes pain leading to primary dysmenorrhea ${ }^{9}$.

The risk factors for dysmenorrhea are: age < 20 years, nulliparity, heavy menstrual flow, smoking, upper socioeconomic status, attempts to lose weight, physical inactivity, disruption of social networks, depression and anxiety. Some of the symptoms of dysmenorrhea are backache, vomiting, nausea, diarrhea, Fatigue, mood changes and breast tenderness. ${ }^{10}$

Usually pain begins from the first day of menstrual cycle and lasts up to two days ${ }^{11}$.

Various relaxation technique can be used in relieving pain and improving quality of life in women's with primary dysmenorrhea. Two techniques used in this study.
Laura Mitchell's physiological Relaxation therapy which is effective in improving immune functions, decreasing depression and improving quality of life.

Mitchell's muscle relaxation technique is based on physiological principle of reciprocal inhibition and involves diaphragmatic breathing. When one group of muscles acting on a joint is working, the opposing group relaxes. In Laura Mitchell relaxation technique there is involvement of reciprocal relaxation, where one part of the body is moved in the opposite direction from an area of tension, and then letting it go.

Jacobson relaxation technique involves flexing specific muscles, holding that position and then relaxing the muscles. This technique often involves progressing through the muscle groups of the body one at a time, beginning with the feet, spending approximately one minute on each area ${ }^{12}$.

No study has been done to compare the effects of these relaxation techniques in primary dysmenorrhea. Hence, we have compared Laura Mitchell's physiological relaxation technique and Jacobson's progressive relaxation technique to see which is more effective on severity of pain and quality of life in primary dysmenorrhea.

\section{MATERIALS AND METHODS}

Subjects were screened using moos menstrual distress questionnaire. All were screened for inclusion and exclusion criteria. The purpose of the study was explained and a written informed consent was obtained from all the subjects.

The subjects were randomly allocated into 2 groups viz. Group A and group B. All the subjects were assessed pre- intervention and postintervention using numeric pain rating scale and American chronic pain association quality of life. Group A subjects were given Laura Mitchell's progressive relaxation technique and Group B participants were given Jacobson's progressive relaxation technique for 30 minutes, for two consecutive menstrual cycles. Subjects were assessed twice for severity of pain and quality of 
life using numeric pain rating scale and American chronic pain association quality of life scale respectively, pre- intervention i.e. at the beginning of first menstrual cycle and post- intervention i.e. at the end of first menstrual cycle and same was repeated for second consecutive menstrual cycle.

\section{INTERVENTION}

Group A - Laura Mitchell's physiological relaxation technique

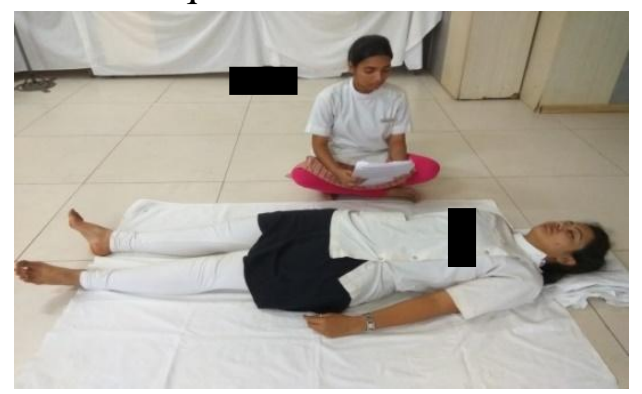

Treatment procedure: She was instructed to assume a comfortable half lying or supine position on a firm surface by using pillows and cushions to accommodate her body curves. She was fully supported and her body parts were relaxed as well as, there was no muscle tension. Her mouth and eyes was gently kept closed. The voice of the instructor used during relaxation training was smooth and quiet. Gradually reducing in volume as the session was progressed. After that, she was instructed to perform the following:

1) Dragging her jaw downwards inside her mouth. Then, she has to stop this action and feel the new position.

2) Pressing her tongue downwards in her mouth. Then, she has to stop this action and feel it.

3) Closing her eyes gently if they are open, keeping her eyelids down, then she has to stop and she was asked to feel and enjoy the peace of darkness.

4) Pushing her head downwards against the bed, then stop this action and note the bed carried weight of her head.

5) Pulling her shoulders towards her feet, feeling the space between her shoulders and her ears, then stop this action and feel the new position.
6) Sliding her elbows sideways away from her body until she reaches a comfortable point. Then, she was asked to stop moving and feel the space between her arms and her body.

7) Abducting and extending (stretching and separating) her fingers and thumbs with the palmer surface of both hands rested on the bed. Then, stopping and noting how her hands feel, spending one or two moment taking these sensation.

8) Breathing slowly and deeply without putting any effort into her breathing or any change in its rhythm.

9) Rolling her thighs outwards (external rotation). Stopping, letting her legs settled comfortably and noting how they feel in this position.

10) Moving her knees until they are comfortable, adjusting their positions to enhance their comfort. Stopping and registering the sense of ease.

11) Planter flexing her feet away from her face being careful not to induce cramp. Stopping and feeling the new position of her feet.

12) Pushing her body downwards against the bed. Stopping, then, feeling her body weight being supported and noting the points where her body touch the bed.

13) Thinking of a smoothing action which will begin above her eye brows, move up into hair line, continued over the crown of her head and down to the back of her neck. Enjoying this effect.

Then, she was instructed to slowly return to the active state gradually to avoid fainting. She Was asked to open her eyes, being aware of the room, give her limbs a gentle stretches and her body plenty of time to be adjusted to an active state. This technique was performed for thirty minutes per session, for 2 consecutive menstrual cycles. Group B - Jacobson's progressive relaxation technique 


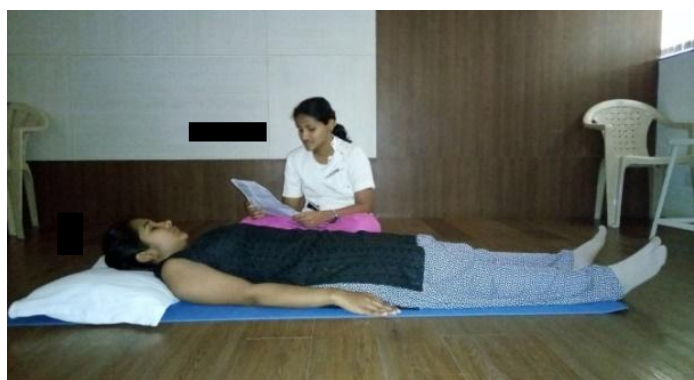

Following instructions was given to the patients:-

1) Take three deep abdominal breaths, exhaling slowly each time. As you exhale, imagine that tension throughout your body begins to flow away.

2) Clench your fists. Hold for 7-10 seconds and then release for 15-20 seconds. The same time intervals was used for all other muscle groups.

3) Tighten your biceps by drawing your forearms up towards your shoulders with both arms. Hold and relax.

4) Tighten your triceps by extending your arms out straight and lock your elbows. Hold and then relax.

5) Tense the muscles in your forehead by raising your eyebrows as far as you can. Hold and then relax. Imagine your forehead muscles becoming smooth and limp as they relax.

6) Tense the muscles around your eyes by clenching your eyelids tightly shut. Hold and then relax. Imagine sensations of deep relaxation spreading all around you.

7) Tighten your jaws by opening your mouth so widely that you stretch the muscles around the hinges of your jaw. Hold and then relax. Let your lips part and allow your jaw to hang loose.

8) Tighten the muscles in the back of your neck by pulling your head way back; as you are going to touch your head to your back. Hold and then relax.

9) Take a few deep breaths and tune in to the weight of your head sinking into whatever surface it is resting on.
10) Tighten your shoulders by raising them up as if you are going to touch your ears. Hold and then relax.

11) Tighten the muscles around your shoulder blades by pushing your shoulder blades back as if you are going to touch them together. Hold the tension in your shoulder blades and then relax.

12) Tighten the muscles of your chest by taking in a deep breath. Hold for up to 10 seconds and then release slowly. Imagine any excess tension in your chest flowing away with the exhalation.

13) Tighten your stomach muscles by sucking your stomach in. Hold and then release. Imagine a wave of relaxation spreading through your abdomen.

14) Tighten your lower back by arching it up. Hold and then relax.

15) Tighten your buttocks by pulling them together. Hold and then relax. Imagine the muscles in your hips going loose and limp.

16) Squeeze the muscles in your thighs all the way down to your knees. Hold and then relax. Feel your thigh muscles smoothening out and relaxing completely.

17) Tighten your calf muscles by-pulling your toes towards you. Hold and then relax.

18) Now imagine a wave of relaxation slowly spreading throughout your body, starting at your head and slowly penetrating every muscle groups all the way down to your toes.

\section{RESULT}

Table 1: Comparison of Group A and Group B with respect to mean age and BMI scores by t test

\begin{tabular}{|l|c|c|c|c|c|c|}
\hline Variable & Group & Mean & SD & SE & t-value & p-value \\
\hline \multirow{2}{*}{ Age in yrs } & Group A & 19.88 & 1.65 & 0.40 & -0.3323 & 0.7418 \\
\cline { 2 - 5 } & Group B & 20.06 & 1.43 & 0.35 & & \\
\hline \multirow{2}{*}{ Height in cms } & Group A & 156.12 & 5.96 & 1.44 & -0.6636 & \multirow{2}{*}{0.5117} \\
\cline { 2 - 5 } & Group B & 157.59 & 6.93 & 1.68 & & \\
\hline Weight in kgs & Group A & 54.65 & 6.35 & 1.54 & -1.1267 & \multirow{2}{*}{0.2682} \\
\cline { 2 - 5 } & Group B & 58.12 & 11.02 & 2.67 & & \\
\hline \multirow{2}{*}{ BMI } & Group A & 22.18 & 2.17 & 0.53 & -0.7761 & \multirow{2}{*}{0.4434} \\
\cline { 2 - 5 } & Group B & 23.21 & 5.01 & 1.21 & & \\
\hline
\end{tabular}




\section{JMSCR Vol||05||Issue||07||Page 25379-25387||July}

Table 2: Comparison of two study groups (Group A and Group B) with respect to onset of period (yrs) by t test

\begin{tabular}{|l|c|c|c|c|c|c|}
\hline Groups & $\mathrm{N}$ & Mean & $\mathrm{SD}$ & $\mathrm{SE}$ & $\mathrm{t}$-value & P-value \\
\hline Group A & 17 & 13.71 & 1.45 & 0.35 & 1.9345 & 0.0619 \\
\hline Group B & 17 & 12.88 & 0.99 & 0.24 & & \\
\hline
\end{tabular}

Table 3 : Comparison of two study groups (Group A and Group B) with respect to length of cycle (days) by $\mathrm{t}$ test

\begin{tabular}{|l|c|c|c|c|c|c|}
\hline Groups & $\mathrm{N}$ & Mean & $\mathrm{SD}$ & $\mathrm{SE}$ & $\mathrm{t}$-value & P-value \\
\hline Group A & 17 & 31.18 & 2.43 & 0.59 & 0.1328 & 0.8952 \\
\hline Group B & 17 & 31.06 & 2.73 & 0.66 & & \\
\hline
\end{tabular}

Table 4 : Comparison of two study groups (Group A and Group B) with respect to length of period by t test

\begin{tabular}{|l|c|c|c|c|c|c|}
\hline Groups & $\mathrm{N}$ & Mean & $\mathrm{SD}$ & $\mathrm{SE}$ & $\mathrm{t}$-value & P-value \\
\hline Group A & 17 & 5.24 & 0.66 & 0.16 & 1.2184 & 0.2320 \\
\hline Group B & 17 & 4.88 & 0.99 & 0.24 & & \\
\hline
\end{tabular}

Table 5: Comparison of two study groups (Group A and Group B) with respect to MMDQ scores by $\mathrm{t}$ test

\begin{tabular}{|l|c|c|c|c|c|c|}
\hline Groups & $\mathrm{n}$ & Mean & $\mathrm{SD}$ & $\mathrm{SE}$ & $\mathrm{t}$-value & P-value \\
\hline Group A & 17 & 91.76 & 25.16 & 6.10 & 0.5267 & 0.6020 \\
\hline Group B & 17 & 88.00 & 15.34 & 3.72 & & \\
\hline
\end{tabular}

Table 6: Comparison of Group A and Group B with respect to numerical pain scores in $1^{\text {st }}$ cycle at pretest and posttest time points by independent $t$ test

\begin{tabular}{|c|c|c|c|c|c|c|}
\hline \multirow[t]{2}{*}{ Groups } & \multicolumn{2}{|c|}{ Pretest } & \multicolumn{2}{|c|}{ Posttest } & \multicolumn{2}{|c|}{ Changes } \\
\hline & $\begin{array}{c}\text { Mea } \\
\mathrm{n}\end{array}$ & SD & $\begin{array}{c}\text { Mea } \\
n\end{array}$ & $\mathrm{SD}$ & Mean & $\mathrm{SD}$ \\
\hline Group A & 7.06 & $\begin{array}{c}1.3 \\
0 \\
\end{array}$ & 3.53 & $\begin{array}{c}1.1 \\
2\end{array}$ & 3.53 & 0.94 \\
\hline Group B & 7.88 & $\begin{array}{c}1.1 \\
7\end{array}$ & 4.24 & $\begin{array}{c}1.3 \\
0\end{array}$ & 3.65 & 0.93 \\
\hline $\begin{array}{l}\% \text { of change in group } \\
\text { A }\end{array}$ & & & & & \multicolumn{2}{|c|}{$\begin{array}{r}50.00 \% \#, \\
\mathrm{p}=0.0001 *\end{array}$} \\
\hline $\begin{array}{l}\% \text { of change in group } \\
\text { B }\end{array}$ & & & & & \multicolumn{2}{|c|}{$\begin{array}{l}46.27 \% \#, \\
\mathrm{p}=0.0001 *\end{array}$} \\
\hline t-value & \multicolumn{2}{|c|}{-1.9461} & \multicolumn{2}{|c|}{-1.6928} & \multicolumn{2}{|c|}{-0.3659} \\
\hline P-value & \multicolumn{2}{|c|}{0.0605} & \multicolumn{2}{|c|}{0.1002} & \multicolumn{2}{|c|}{0.7168} \\
\hline
\end{tabular}

$* \mathrm{p}<0.05$, \#applied dependent $\mathrm{t}$ test
Table 7: Comparison of Group A and Group B with respect to numerical pain scores in $2^{\text {nd }}$ cycle at pretest and posttest time points by independent $t$ test

\begin{tabular}{|c|c|c|c|c|c|c|}
\hline \multirow[t]{2}{*}{ Groups } & \multicolumn{2}{|c|}{ Pretest } & \multicolumn{2}{|c|}{ Posttest } & \multicolumn{2}{|c|}{ Changes } \\
\hline & $\begin{array}{c}\text { Mea } \\
n\end{array}$ & SD & $\begin{array}{c}\text { Mea } \\
n\end{array}$ & SD & Mean & SD \\
\hline Group A & 6.18 & $\begin{array}{c}1.0 \\
1\end{array}$ & 2.53 & $\begin{array}{c}1.2 \\
3\end{array}$ & 3.65 & 0.79 \\
\hline Group B & 6.71 & $\begin{array}{c}1.0 \\
5\end{array}$ & 3.29 & $\begin{array}{c}1.2 \\
6\end{array}$ & 3.41 & 0.87 \\
\hline $\begin{array}{l}\% \text { of change in group } \\
\text { A }\end{array}$ & & & & & \multicolumn{2}{|c|}{$\begin{array}{l}59.05 \% \#, \\
p=0.0001 *\end{array}$} \\
\hline $\begin{array}{l}\% \text { of change in group } \\
\text { B }\end{array}$ & & & & & \multicolumn{2}{|c|}{$\begin{array}{l}50.88 \% \#, \\
\mathrm{p}=0.0001 *\end{array}$} \\
\hline t-value & \multicolumn{2}{|c|}{-1.4974} & \multicolumn{2}{|c|}{-1.7878} & \multicolumn{2}{|c|}{0.8273} \\
\hline P-value & \multicolumn{2}{|c|}{0.1441} & \multicolumn{2}{|c|}{0.0833} & \multicolumn{2}{|c|}{0.4142} \\
\hline
\end{tabular}

*p $<0.05$, \#applied dependent $\mathrm{t}$ test

Table 8: Comparison of Group A and Group B with respect to quality of life scores in $1^{\text {st }}$ cycle at pretest and posttest time points by independent $t$ test

\begin{tabular}{|c|c|c|c|c|c|c|}
\hline \multirow[t]{2}{*}{ Groups } & \multicolumn{2}{|c|}{ Pretest } & \multicolumn{2}{|c|}{ Posttest } & \multicolumn{2}{|c|}{ Changes } \\
\hline & $\begin{array}{c}\text { Mea } \\
n\end{array}$ & SD & $\begin{array}{c}\text { Mea } \\
\mathrm{n}\end{array}$ & SD & Mean & SD \\
\hline Group A & 5.76 & $\begin{array}{c}1.6 \\
8\end{array}$ & 7.82 & 0.81 & 2.06 & 1.25 \\
\hline Group B & 5.24 & $\begin{array}{c}1.9 \\
5\end{array}$ & 7.65 & 1.46 & 2.41 & 0.87 \\
\hline $\begin{array}{l}\% \text { of change in group } \\
\mathrm{A}\end{array}$ & & & & & \multicolumn{2}{|c|}{$\begin{array}{l}35.71 \% \#, \\
\mathrm{p}=0.0001 \%\end{array}$} \\
\hline $\begin{array}{l}\% \text { of change in group } \\
\mathrm{B}\end{array}$ & & & & & \multicolumn{2}{|c|}{$\begin{array}{l}46.07 \% \#, \\
\mathrm{p}=0.0001 \%\end{array}$} \\
\hline t-value & \multicolumn{2}{|c|}{0.8476} & \multicolumn{2}{|c|}{0.4370} & \multicolumn{2}{|c|}{-0.9562} \\
\hline $\mathrm{P}$-value & \multicolumn{2}{|c|}{0.4030} & \multicolumn{2}{|c|}{0.6650} & \multicolumn{2}{|c|}{0.3461} \\
\hline
\end{tabular}

Table 9: Comparison of Group A and Group B with respect to quality of life scores in 2nd cycle at pretest and posttest time points by independent $t$ test

\begin{tabular}{|c|c|c|c|c|c|c|}
\hline \multirow[t]{2}{*}{ Groups } & \multicolumn{2}{|c|}{ Pretest } & \multicolumn{2}{|c|}{ Posttest } & \multicolumn{2}{|c|}{ Changes } \\
\hline & Mean & SD & $\begin{array}{c}\text { Mea } \\
\mathrm{n}\end{array}$ & SD & Mean & $\mathrm{SD}$ \\
\hline Group A & 6.65 & $\begin{array}{c}1.2 \\
2\end{array}$ & 8.53 & $\begin{array}{c}0.5 \\
1\end{array}$ & 1.88 & 1.17 \\
\hline Group B & 5.88 & $\begin{array}{c}1.5 \\
8\end{array}$ & 8.29 & $\begin{array}{c}0.7 \\
7\end{array}$ & 2.41 & 1.33 \\
\hline $\begin{array}{l}\% \text { of change in } \\
\text { group A }\end{array}$ & & & & & & b1* \\
\hline $\begin{array}{l}\% \text { of change in } \\
\text { group B }\end{array}$ & & & & & & $01 *$ \\
\hline t-value & 1.58 & & & & & \\
\hline P-value & 0.12 & & 0.3 & & & \\
\hline
\end{tabular}


Age distribution: Age of the participants in the study was between 18 to 22 years. The mean age of the participants in group A was 19.88 years, the mean age of participants in group B was 20.06 years. (Table 1)

Body mass index: In group A, the mean BMI of participants was 22.18 and in group $\mathrm{B}$, the mean BMI of the participants was 23.21. The p value by paired $t$ test was found to be 0.0001 in both the groups which is highly significant. When compared between the two groups mean BMI showed not much statistical difference. (Table 1)

Onset of period: In group A, the mean onset of period was 13.71 and in group B was 12.88 . The $\mathrm{p}$ value was found to be 0.0001 in both the groups which is highly significant. On comparing within group showed significant difference but when compared within the groups, 'p' value showed no statistical difference. (Table 2)

Length of cycle: In group A, the mean length of cycle was 31.18 and in group B was 31.06. when compared in the groups ' $p$ ' value was found to be significant. When compared between the groups 'p' value showed no statistical difference. (Table 3)

Length of period: In group A, the mean length of period was 5.24 and in group B was 4.88 . when compared in the groups ' $p$ ' value was found to be significant. When compared between the groups 'p' value showed no statistical difference. (Table 4)

Moos menstrual distress questionnaire: In group $\mathrm{A}$, the mean of moos menstrual distress questionnaire was 91.76 and in group B was 88.00. On comparing the two groups, the result showed that there is slight statistical difference between group A and group B.( Table 5)

Numeric pain rating scale in $1^{\text {st }}$ menstrual cycle: In group A, Pre test mean of numeric pain rating scale was $7.06 \pm 1.30$ and post test was $3.53 \pm 1.12$ and in group $B$, Pre test was $7.88 \pm 1.17$ and post test was $4.24 \pm 1.30$. The percentage of change in group A , was $50.00 \%$ and group B showed $46.27 \%$. On comparing both the groups, group A was found to be better than group B and showed significant reduction in the severity of pain of participants from group A . (Table 6)

Numeric pain rating scale in $2^{\text {nd }}$ menstrual cycle: In group A, Pre test mean of numeric pain rating scale was $6.18 \pm 1.01$ pretest and post test was $2.53 \pm 1.23$ and in group B pre test was $6.71 \pm 1.05$ and post test was $3.29 \pm 1.26$. The percentage of change in group A was $59.05 \%$ and group B showed $50.88 \%$. On comparing both the groups, group A was found to be better than group $\mathrm{B}$ and showed significant reduction in the severity of pain of participants from group A. (Table 7)

Quality of life scores in $\mathbf{1}^{\text {st }}$ cycle: In group A, Pre test quality of life scores was $5.76 \pm 1.68$ and Post test was $7.85 \pm 0.81$ and in group $B$, Pre testo $f$ quality of life scores was $5.24 \pm 1.95$ and Post test was $7.65 \pm 1.46$. The percentage of change in group A was $35.71 \%$ and group B showed $46.07 \%$. On comparing both the groups, group B was found to be better than group A and showed significant improvement in the quality of life of participants from group B . (Table 8)

Quality of life scores in $\mathbf{2}^{\text {nd }}$ cycle: In group A, Pre test quality of life scores was $6.65 \pm 1.22$ and Post test was $8.53 \pm 0.51$ and in group B, Pre test quality of life scores was $5.88 \pm 1.58$ and Post test was $8.29 \pm 0.77$. The percentage of change in group A was $28.32 \%$ and group B showed $41.00 \%$. Hence on comparing both the groups, group B was found to be better than group A and showed significant improvement in the quality of life of participants from group B. (Table 9)

\section{DISCUSSION}

The present study was conducted to compare the effect of Laura Mitchell's physiological relaxation technique and Jacobson's progressive relaxation technique on severity of pain and quality of life in primary dysmenorrhea. In this study, 34 subjects were randomly allocated into two groups. All the subjects were screened using MMDQ scale.

Each group were give relaxation techniques for 30 minutes, twice a day for two consecutive menstrual cycles. 
Relaxation techniques are known to be effective in improving immune function, decreasing depression and improving quality of life. It is also proved to be beneficial in reducing anxiety and stress. Hence it is considered to be effective in improving psychological health in human beings. In the present study it was found that the prevalence of primary dysmenorrhea was $90 \%$ among the college going girls.

In present study age group of subjects was 18-22 years. Statistical analysis showed significant difference in the age between both the groups. Similar findings were found in the study done by Nahid Rahbaret al $^{13}$

Similar study done by Soheir M. A. El Kosery et al showed same age group to the present study.

In present study BMI analysis showed no significant difference, hence we can conclude that all subjects were not obese. This was true to the study done by Maitri Shah et al ${ }^{14}$.

Study done by Maryam Kabirian et al which is similar to the present study concluded that there was no significant difference between the two groups with regard to onset of period ${ }^{15}$.

Study conducted by Nazan Tugay et al where they assessed the effectiveness of transcutaneous electrical nerve stimulation and interferential current in primary dysmenorrhea where the mean of length of menstrual cycle was 27.33 and 27.07 which is less than the mean of length of menstrual cycle in present study ${ }^{16}$.

Study carried out by Nazan Tugay et al where they assessed the effectiveness of transcutaneous electrical nerve stimulation and interferential current in primary dysmenorrhea where the length of period was 5.87 and 5.12 in both the groups which is almost similar to the mean of length of period in present study Based on the analysis of length of period, this study suggest that there is no much significant difference between both the groups.

Moos menstrual distress questionnaire was used to screen primary dysmenorrhea where scores of group A was more than group B. Similar scale was used in the study done by Susan L Hendrix et $\mathrm{al}^{17}$.

Pain intensity was measured for two consecutive cycles by using Numeric pain rating scale, on analysis there was reduction in intensity of pain .Similar findings was found in the study done by GitiOzgoli et $\mathrm{al}^{18}$.

American chronic pain association quality of life scale was used to assess quality of life, pre and post intervention for two consecutive menstrual cycles. Both groups showed significant improvement in quality of life, these findings were similar to the study done by Ganesh B.R et $\mathrm{al}^{19}$.

Study conducted by Soheir M. A. El Kosery et al. to determine the effects of Mitchell's simple physiological relaxation technique in alleviating pain and tension of primary dysmenorrhea. It concluded that this technique was found to be effective, non- invasive, safe, cheap, easy to perform and successful treatment method in reducing pain and tension of primary dysmenorrhea. Similar findings was found in the present study by using Mitchell's physiological relaxation technique.

Study done by Lehrer PM, to evaluate the effect of Jacobson's method of progressive relaxation over modified techniques that suggest brevity and the feeling of large contrasts between tension and relaxation. Study concluded that Jacobson's progressive muscle relaxation is more effective inpsychophysiological symptoms compared to modified techniques ${ }^{20}$.

Hence the present study states that both the relaxation techniques can be used to relieve physiological stress and improve quality of life in subjects with primary dysmenorrhea and should be practiced on daily basis.

Both the techniques used in the present study are easy to adopt, self administered with no side effects which has beneficial effect in pain reduction, reducing absenteeism thus improving quality of life .Self esteem of the subjects can also be improved by using these simple relaxation exercises. 


\section{LIMITATIONS OF THE STUDY}

> Study group included only Physiotherapy girls students.

$>$ Investigator was not blinded.

$>$ Follow up was not done.

\section{FUTURE SCOPE}

$>$ Individual components of moos menstrual distress questionnaire can be taken in to consideration.

$>$ Studies using different outcome measures like heart rate, pulse rate, blood pressure, EMG biofeedback can be planned.

$>$ Studies using different age group can be planned.

$>$ Long follow up studies can be planned.

$>$ Larger sample size and a longer follow up period should be considered.

\section{CONCLUSION}

Laura Mitchell's physiological relaxation technique is more effective in reducing severity of pain and Jacobson's progressive relaxation techniques is more effective in improving quality of life in primary dysmenorrhea. Both the techniques can be used clinically to reduce symptoms and improves quality of life and reduce absenteeism and stress levels and it is easy, cheap and has no side effects, so it should be implemented in college students to augment their menstrual wellbeing and should be inculcated as a routine practice to improve quality of life.

\section{ACKNOWLEDGMENT}

We would like to thank all the Participants of this study without whom this study would have been impossible.

Conflict of interest: none.

\section{REFENCES}

1. Saleh HS, Mowafy HE, El Hameid AA. Stretching or Core Strengthening Exercises for Managing Primary Dysmenorrhea. J Women's Health Care. 2016;5(295):2167-0420.
2. Steptoe A, Hamer M, ChidaY.. The effects of acute psychological stress on circulating inflammatory factors in humans: A review and mata analysis. Brain Behavior and Immunity 2007;21: 901-912.

3. El Kosery SM, Saleh A, Farouk A. Efficacy of Mitchell's Simple Physiological Relaxation Technique in Alleviating Primary Dysmenorrhea. Bull. Fac. Ph. Th. Cairo Univ. 2006 Jan;11(1).

4. Unsal A, Ayranci U, Tozun M, Arslan G, Calik E. Prevalence of dysmenorrhea and its effect on quality of life among a group of female university students. Upsala journal of medical sciences. 2010 May 1;115(2):138-45.

5. Banikarim C, ChackoMr, Kelder SH. Prevalence and impact of dysmenorrhea on Hispanic female adolescents. Arch pediatrAdolesc Med 2000 Dec;154:122629.

6. Lee LK, Chen PCY, Lee KK, Kaur J. Menstruation among adolescent girls in Malaysia: a cross- sectional school survey. Singapore Med J 2006;47(10):874.

7. Pilkington $\mathrm{K}$, Kirkwood $\mathrm{G}$, Rampes $\mathrm{H}$, Richardson J, Yoga for depression: The research evidence. J Affected Disord 2005;89:13-24.

8. Andersch B, Milsom I. An epidemiologic study of young women with dysmenorrhea Am J ObstetGynecol 1982;144:655-660.

9. Reis CA, Hardy E, Sousa MH. The effectiveness of connective tissue massage in the treatment of primary dysmenorrhea among young women. RevistaBrasileira de SaúdeMaternoInfantil. 2010 Jun;10(2):247-56.

10. Cakir M, Mungan I, Karakas T, Girisken I, Okten A. Menstrual pattern and common menstrual disorders among university students in Turkey. PediatrInt 2007 Dec;49(6):938-942.

11. Mahishale A, Mascarenhas D, Patted S. Effect of Knee Chest Position in 
Banikarim C, ChackoMr, Kelder SH. Prevalence and impact of dysmenorrhea on Hispanic female adolescents. Arch pediatrAdolesc Med 2000 Dec;154:122629.

12. Profile VY, Finder MP. Relaxation therapy.

13. Rahbar N, Asgharzadeh N, Ghorbani R. Effect of omega-3 fatty acids on intensity of primary dysmenorrhea. International Journal of Gynecology\& Obstetrics. 2012 Apr 1;117(1):45-7.

14. Shah M, Monga A, Patel S, Shah M, Bakshi H. A study of prevalence of primary dysmenorrhea in young students-a cross-sectional study. Healthline, Journal of Indian Association of Preventive and Social Medicine. 2013;4(2):30-4.

15. Kabirian M, Abedian Z, Mazlom SR, Mahram B, Jalalian M. Self-management in primary dysmenorrhea: toward evidence-based education. Life Sci J. 2011 May;8(2):13-8.

16. Tugay N, Akbayrak $\mathrm{T}$, Demirtürk $\mathrm{F}$, Karakaya II, Kocaacar Ö, Tugay U, Karakaya MG, Demirtürk F. Effectiveness of transcutaneous electrical nerve stimulation and interferential current in primary dysmenorrhea. Pain Medicine. 2007 May 1;8(4):295-300.

17. Hendrix SL, Alexander NJ. Primary dysmenorrhea treatment with a desogestrel-containing low-dose oral contraceptive.Contraception . 2002 Dec 31;66(6):393-9.

18. Ozgoli G, Goli M, Moattar F. Comparison of effects of ginger, mefenamic acid, and ibuprofen on pain in women with primary dysmenorrhea. The journal of alternative and complementary medicine . 2009 Feb 1;15(2):129-32.

19. Ganesh BR, Madhushree PD, Andrea RH. Comparative study on effect of slow and fast phased pranayama on quality of life and pain in physiotherapy girls with primary dysmenorrhea : Randomized clinical trial. Int $\mathbf{J}$ Physiother Res. 2015;3(2):928-37.

20. Lehrer PM. How to relax and how not to relax: A re-evaluation of the work of Edmund Jacobson-I. Behaviour Research and Therapy. 1982 Jan 1;20(5):417-28. 